\title{
An effective invasive therapeutic approach of fluoro-substituted zinc phthalocyanine derivatives as potential photosensitizer for prostate carcinoma
}

\author{
Tamer E. Youssef ${ }^{\mathrm{a}, \mathrm{b}, *}$, Suhailah S. Al-Jameel ${ }^{\mathrm{a}}$, Wafa M. Al-Magribi ${ }^{\mathrm{a}}$ \\ a Department of Chemistry, College of Science, Imam Abdulrahman Bin Faisal University, \\ Dammam 31441 Saudi Arabia. \\ b Basic and Applied Scientific Research Center, Imam Abdulrahman Bin Faisal University, \\ Dammam 31441 Saudi Arabia.
}

*Corresponding author, e-mail: temoustafa@iau.edu.sa

Received 14 Jun 2020

Accepted 30 Sep 2020

\begin{abstract}
Fluoro-substituted zinc(II)phthalocyanines (RS) ${ }_{4} \mathrm{ZnPcs}$ were prepared. All the structures of newly synthesized compounds was evaluated by IR and ${ }^{1} \mathrm{H}$ NMR spectral analysis. They were tested against human adenocarcinoma prostate cancer cells. A type II membrane antigen highly expressed in prostate cancer, namely prostate-specific membrane antigen, has been an attractive target for imaging and therapy. To investigate the structureactivity relationships of (RS) ${ }_{4} \mathrm{ZnPcs} 4 \mathrm{a}-\mathrm{c}$ in human adenocarcinoma prostate cancer cell model, 3 fluoro-substituted zinc(II)phthalocyanines with different terminal heteroaromatic rings have been designed and evaluated for their antiproliferative potency in vitro. The detailed LD50 values of the targeted compounds were reported. Our preliminary in vitro studies confirm that (RS) ${ }_{4} \mathrm{ZnPcs} 4 \mathrm{a}-\mathrm{c}$ could act as an attractive photosensitizer for the early diagnosis of prostate cancer.
\end{abstract}

KEYWORDS: zinc phthalocyanine, cancer therapy, prostate cancer cell line

\section{INTRODUCTION}

Phthalocyanines (Pcs) - especially, metallophthalocyanines bearing an aluminum, zinc, indium, or silicon as a central metal atom - are excellent photosensitizers (PSs) (second generation) for photodynamic therapy (PDT) in several types of tumors [1]. They offer effective properties for an ideal PS [2]. They are absorbed in the red and near infrared regions of the visible spectrum [3]. In addition, Pcs have high photo and chemical stability [4].

Zinc phthalocyanines (ZnPcs) are valuable PSs [5-10]. When they functionalized with heterocycles units such as 4-pyridylmethyloxy and pyridyloxy groups $[11,12]$, adamantylethoxy zinc phthalocyanines [13], hexadecafluoro zinc phthalocyanine [14], tetracarboxy zinc phthalocyanine [15] with pentalysine peptidyl moiety (ZnPc(Lys) ${ }_{5}$ ) [16]. A number of cell lines [17-19] showed the efficiency of zinc phthalocyanines as photosensitizers as a result of their excellent fluorescence quantum yields [20,21]. Recent advances in drug-delivery caused by zinc phthalocyanines are commonly used in cancer treatment with an additional benefit including the enhancement of drug- therapeutic efficiency. It enhances the pharmacological properties by altering pharmacokinetics. In addition, it improves the drug hydro-solubility and drug half-life [22]. Prostate cancer is the second highest cancer mortality in American men. There are 238590 new cases of prostate cancer examined. Also, 720 men died due to the prostate cancer in the United States in 2013. The local radiotherapy, radical prostatectomy, chemotherapy, or hormonotherapy is used in treating localized prostate cancer [23].

Prostate-specific membrane antigen (PSMA) is a membrane-bound glycoprotein. It presents in the human prostate adenocarcinoma cell line from hormone-refractory patients [24]. In addition, PSMA is a talented target for treatment of prostate cancer [25]. Previously, Liu et al [26] reported PSMA inhibitors for targeted PDT in vitro. Watanabe et al [27] reported recently effective PSMAtargeted photoimmunotherapy. It targets both full antibodies and antibody fragments. Synthesized fluorinated compounds such as steroids containing 5-Fluorouracil revealed high potential therapeutic effect with implications to biological activities [28].

In this sense, zinc phthalocyanines substituted 
with fluorine atoms are becoming the most appealing answer to solve chemotherapy problems such as degradation and nonspecific toxicity [29]. In addition, Chen et al [30] used a PSMA-targeted LysGlu-Lys urea based theragnostic agent for prostate cancer imaging and PDT. Previously, our group has described series of phthalocyanines with their antitumor activity [31-34]. In the present work, the zinc(II) phthalocyanines carrying trifluoromethyl groups have been prepared. Their biological screening results have been described.

\section{MATERIALS AND METHODS}

\section{Materials}

Fluoro-substituted zinc(II) phthalocyanines, (RS) ${ }_{4}$-ZnPcs, were prepared previously from their thiophenyl phthalonitriles derivatives: $3 a-c$ obtained from 2a-c, 4-methylthiophenol (2a), 4-(trifluoromethyl)thiophenol (2b), and 3,5-bis (trifluoromethyl)thiophenol (2c) as described by Youssef et al [34]. 3-(4,5-dimethylthiazol-2-yl)2,5-diphenyl tetrazolium bromide (MTT) and dimethylsulfoxide (DMSO) were purchased from the Sigma-Aldrich Co. All the other chemicals were of analytical grade and were used without further purification.

\section{Biological screening}

In vitro assay: cell culture

In brief, all in vitro antitumor screening on human adenocarcinoma prostate cancer cells (American Type Culture Collection) has been performed at National Research Centre, Cairo-Egypt. Human adenocarcinoma prostate cancer cell line was obtained from America Type Culture Collection (ATCC) through VACSERA, Cairo, Egypt. Cells were cultured in Roswell Park Memorial Institute medium, RPMI-1640 (Sigma St. Lous, USA). Cells were always incubated at $36^{\circ} \mathrm{C}$ in a humidified atmosphere containing $5 \% \mathrm{CO}_{2}$ and subcultured twice a week. For normal transformed cell line, a similar process was followed [35], and the raw data was filtered to remove erroneous entries.

\section{Statistical analysis}

The experiment values used in statistical analysis were means $\pm \mathrm{SD}$ and repeated more than 3 times. A SPSS 10.0 software program (Student's unpaired two-tailed $t$-test) was used to calculate the differences in the mean values of the measured activities statistically. The probability values of $p<0.01$ were statistically significant.
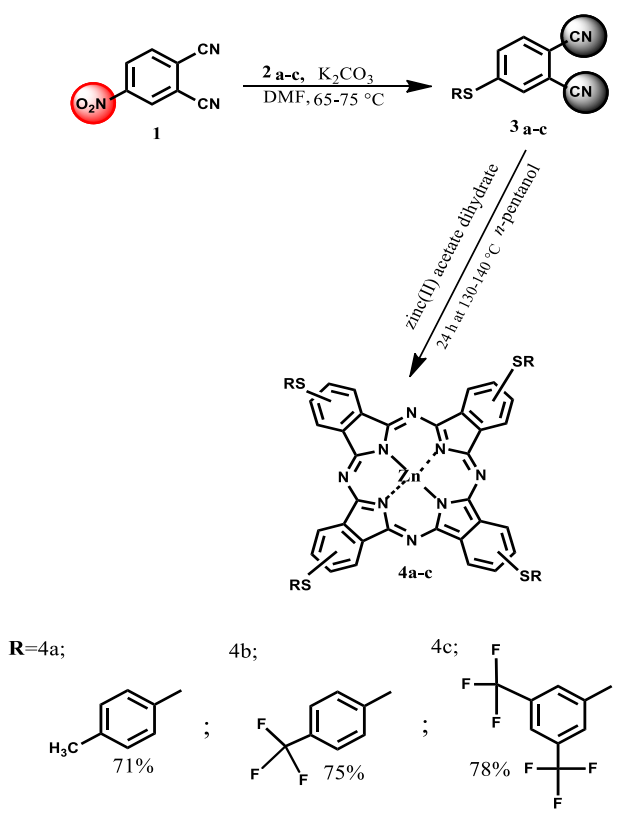

Fig. 1 Reaction pathways of zinc(II) phthalocyanines $(4 a-c)$.

\section{RESULTS AND DICUSSION}

\section{Chemistry}

Zinc(II) phthalocyanines (4a-c) were synthesized from their thiophenyl phthalonitrile derivatives (3a-c) as described previously by Youssef et al [34] with $78 \%$ of the pure phthalonitrile (3a), $70 \%$ (3b) and $62 \%(3 \mathrm{c})$. The general synthetic scheme is shown in Fig. 1 to afford the corresponding 4a-c with 71\% (4a), 75\% (4b), and 78\% (4c) yields.

3a-c precursors were formed with bands at $v=$ $2235-2233 \mathrm{~cm}^{-1}(\mathrm{CN})$ and (SH stretch) at 2595$2596 \mathrm{~cm}^{-1}$ indicated by the FT-IR spectra. The protons of the methyl protons of phtalonitrile $3 \mathrm{a}$ at $\delta=1.44$ (s) ppm and phenyl protons of phtalonitrile $3 \mathrm{a}$ at $8.31-8.42(\mathrm{~m}) \mathrm{ppm}$ were indicated with the ${ }^{1} \mathrm{H}$ NMR spectra and showed non-aggregated spectra. UV-Vis spectroscopy was performed in DMF with constant concentration at $\lambda_{\max }(\mathrm{nm})\left[\left(10^{-5}\right.\right.$ $\left.\left.\log \varepsilon \mathrm{dm}^{3} \mathrm{~mol}^{-1} \mathrm{~cm}^{-1}\right)\right]$. The characteristic Q absorption bands of zinc(II) phthalocyanines (4a-c) with extinction coefficient at around 691(5.51), 686(4.9), and 681(5.16) nm, respectively, (Fig. 2) showed that these compounds are non-aggregated under these aqueous conditions.

\section{In vitro anti-prostate cancer}

In vitro cytotoxicities of the synthesized $\mathrm{Zn}$ (II) phthalocyanine (RS) ${ }_{4} \mathrm{ZnPc}$ derivatives were deter- 


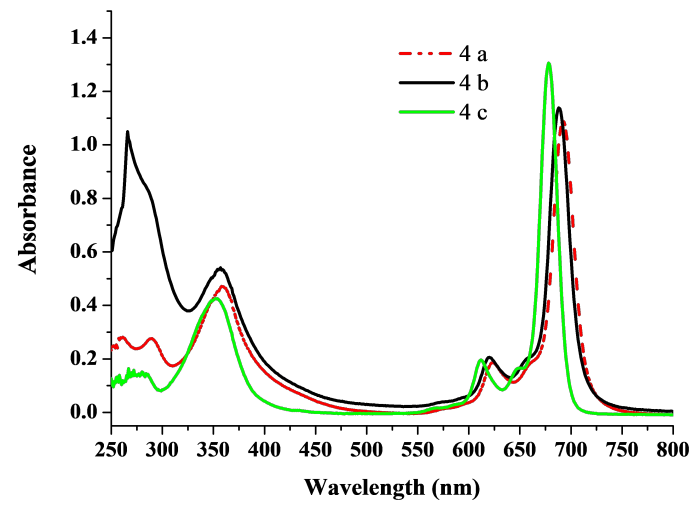

Fig. 2 UV-vis of zinc(II) phthalocyanines (4a-c).

Table $1 \mathrm{IC}_{50}$, KM of zinc(II) phthalocyanines (4a-c) against adenocarcinoma prostate cells.

\begin{tabular}{lc}
\hline Compound no. & $\begin{array}{c}\text { Cytotoxicity }^{\mathrm{a}} \\
\left(\mathrm{IC}_{50}, \mu \mathrm{m}\right) \text { PSMA }\end{array}$ \\
\hline ZnPc 4a & 26.2 \\
ZnPc 4b & 32.7 \\
ZnPc 4c & 7.13 \\
Doxorubicin & 7.05 \\
\hline
\end{tabular}

${ }^{\mathrm{a}} \mathrm{IC}_{50}$ : ZnPc $50 \%$. Values of 3 repeated experiments.

mined by performing prostate cancer cell viability assays. The ability of the $\mathrm{Zn}$ (II) phthalocyanines to inhibit growth of human adenocarcinoma prostate cancer cell lines was measured. A doxorubicin $\mathrm{HCl}$ was used as a reference drug for human adenocarcinoma prostate cancer cells using MTT assay method $[36,37]$. Table 1 shows the results of $\mathrm{LC}_{50}(\mu \mathrm{m})$ as the lethal concentration of (RS) ${ }_{4} \mathrm{ZnPc}$ derivatives to cause death of $50 \%$ of the cells in $24 \mathrm{~h}$.

To study the effect of zinc(II) phthalocyanines $(4 a-c)$ on tumor cell line, namely human adenocarcinoma prostate cancer cells, they were compared with normal human fibroblast healthy cells using MTT assay as shown in Fig. 3. All the tested compounds were found to have potent anti-prostate cancer activities compared to normal cells. They did not exhibit any toxicity against adenocarcinoma prostate cells in the absence of (RS) ZnPcs 4a-c. The structure-activity data acquired indicated that the presence of trifluoromethyl groups $\left(\mathrm{CF}_{3}\right)$ constitutes a promising design novel zinc(II) phthalocyanines with promising cytotoxicity. Previously results with the above method indicated that meta (trifluoromethyl) substituted zinc(II) phthalocyanine is more effective than the corresponding para compound [34]. In comparison with our work, the

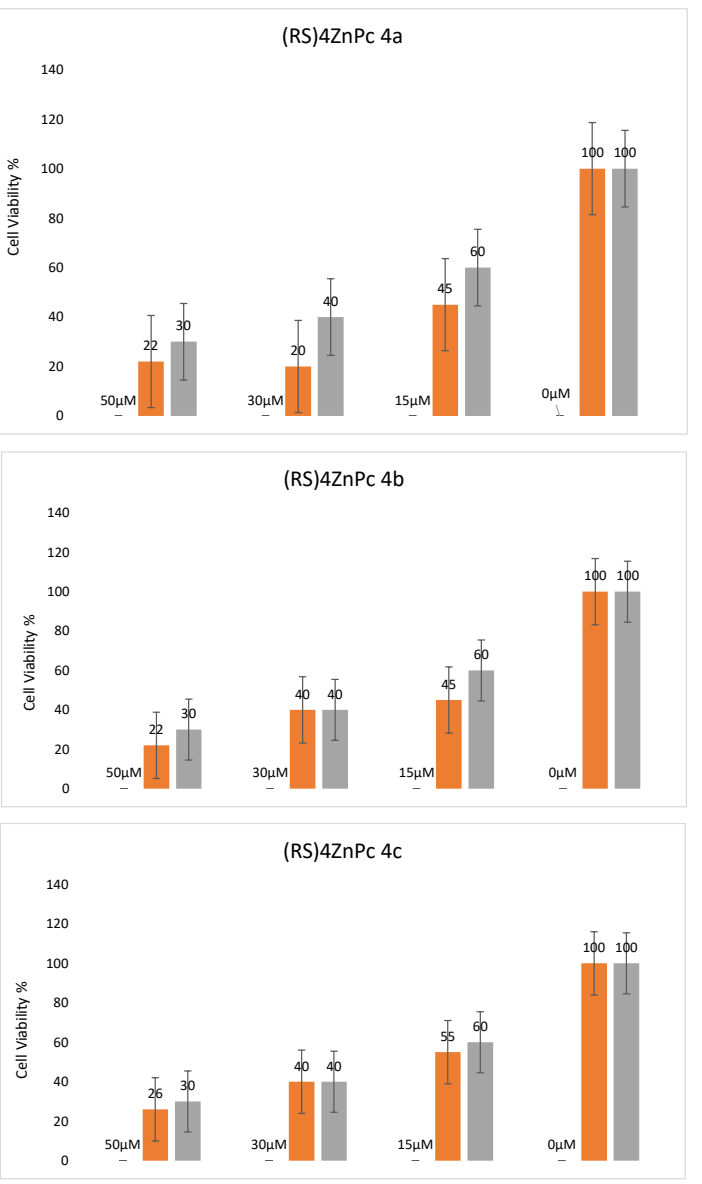

Fig. 3 The proliferation of adenocarcinoma prostate cells (orange bar) and normal cells (grey bar) at different concentrations of (RS) ${ }_{4} \mathrm{ZnPcs} 4 \mathrm{a}-\mathrm{c}$.

bis meta (trifluoromethyl) substituted zinc(II) phthalocyanine compound $4 \mathrm{c}$ showed higher activities compared to those of para compound $4 \mathrm{~b}$, and the order in the antitumor effect is $4 c>4 b>4 a$.

Our work describes the majority of zinc(II) phthalocyanine compounds which are typically common compounds present in most pharmaceuticals. They are intrinsically versatile and have unique physicochemical properties. They showed activity against human adenocarcinoma prostate cancer cells with $\mathrm{IC}_{50}$ values $26.2,32.7$ and $7.13 \mu \mathrm{m}$, respectively, as described in Table 1. All the tested compounds exhibited significant cytotoxicity in human adenocarcinoma prostate cancer.

Imaging has the highest sensitivity for detecting the prostate cancer, in accordance with recent observational study of 925 patients who underwent radiation therapy [38]. Few studies have described 
cases of men with prostate cancer with hypogonadal serum testosterone levels $(<250 \mathrm{ng} / \mathrm{dl}$ ) [39]. Recent studies for chemotherapy dosing recommend the use of body surface area (BSA). Only older patients are expected to be affected significantly with more toxicity from anticancer therapies. It also tends to be under-represented in clinical trials.

Considering preliminary results and the structure - activity study, 4c that contains 8 trifluoromethyl groups $\left(\mathrm{CF}_{3}\right)$ has the most active antitumor activity against human adenocarcinoma prostate cancer cell line $(7.13 \mu \mathrm{m})$. In case of $4 a$, a decrease in the potency against the human adenocarcinoma prostate cancer cell was observed due to the absence of trifluoromethyl groups. The most potent compounds (4b, and 4c) showed impressive cytotoxicity against human adenocarcinoma prostate cancer cell line. It was found $4 \mathrm{c}$ that was effective against human adenocarcinoma prostate cancer cell line. This current study involves in vitro studies because many of the in vivo challenges have not been completely resolved yet. We demonstrated in vitro that zinc(II) phthalocyanines $4 \mathrm{a}-\mathrm{c}$ are effective "cell-killing" agents. They could reach regions deep in the body and be a safe clinical approach.

\section{CONCLUSION}

Zinc(II) phthalocyanines $4 a-c$ have been synthesized and characterized. The synthesized compounds $4 \mathrm{a}-\mathrm{c}$ were evaluated for in vitro anticancer activity. They have activity against human adenocarcinoma prostate cancer cells. The trifluoromethyl groups present at zinc(II) phtalocyanine $4 \mathrm{c}$ has the highest potent activity against the tested cancer cell line as shown in MTT cytotoxicity studies. The structural activity study provided good indication for cancer activity. In human adenocarcinoma prostate cancer cell line, the order in the antitumor effect is $4 c>4 b>4 a$. Taken together, selective enhancement of cell death in aggressive prostate cancer cell line suggests that zinc(II) phtalocyanines $4 \mathrm{a}-\mathrm{c}$ are promising potential compounds. Additional research is needed on mechanism study.

Acknowledgements: The authors would like to thank Department of Pharmacognosy, National Research Center (NRC), Cairo, Egypt, for performing the anticancer activity testing and MTT cytotoxicity assay of the synthesized compounds.

\section{REFERENCES}

1. Yoon I, Li JZ, Shim YK (2013) Advance in photosensitizers and light delivery for photodynamic therapy. Clin Endosc 46, 7-13.

2. Newago M, Constantin C, Tampa M, Matei C, Lupu A, Manole E, Ion RM, Fenga C, et al (2016) Toxicological and efficacy assessment of post-transition metal (Indium) phthalocyanine for photodynamic therapy in neuroblastoma. Oncotarget 7, 69718-69726.

3. Gamal-Eldeen AM, Moustafa D, El-Daly SM, ElHussieny EA (2016) Photothermal therapy mediated by gum Arabic-conjugated gold nanoparticles suppresses liver preneoplastic lesions in mice. $J$ Photochem Photobiol B 163, 47-56.

4. Soriano J, Villanueva A, Stockert JC, Cañete M (2013) Histochem Cell Biol 139, 149-153.

5. Liu JY, Jiang XJ, Fong WP, Ng DK (2008) Highly photocytotoxic 1,4-dipegylated zinc(II) phthalocyanines. Effects of the chain length on the in vitro photodynamic activities. Org Biomol Chem 6, 4560-4566.

6. Liu JY, Lo PC, Fong, Ng DK (2009) Effects of the number and position of the substituents on the in vitro photodynamic activities of glucosylated zinc(II) phthalocyanines. Org Biomol Chem 7, 1583-1591.

7. Rodriguez ME, Diz VE, Awruch J, Dicelio LE (2010) Photophysics of zinc (II) phthalocyanine polymer and gel formulation. Photochem Photobiol 86, 513-519.

8. Lo PC, Zhao B, Duan W, Fong WP, Ko WH, Ng DK (2007) Synthesis and in vitro photodynamic activity of mono-substituted amphiphilic zinc(II) phthalocyanines. Bioorg Med Chem Lett 17, 1073-1076.

9. Choi CF, Huang JD, Lo PC, Fong WP, Ng DK (2008) Glycosylated zinc(II) phthalocyanines as efficient photosensitisers for photodynamic therapy. Synthesis, photophysical properties and in vitro photodynamic activity. Org Biomol Chem 6, 2173-2181.

10. Souza JG, Gelfuso GM, Simao PS, Borges AC, Lopez RF (2011) Iontophoretic transport of zinc phthalocyanine tetrasulfonic acid as a tool to improve drug topical delivery. Anticancer Drugs 22, 783-790.

11. Scalise I, Durantini EN (2005) Synthesis, properties, and photodynamic inactivation of Escherichia coli using a cationic and a noncharged Zn(II) pyridyloxyphthalocyanine derivatives. Bioorg Med Chem 13, 3037-3043.

12. Biylkloglu Z, Durmus M, Kantekin H (2010) Synthesis, photophysical and photochemical properties of quinoline substituted zinc(II) phthalocyanines and their quaternized derivatives. $J$ Photochem Photobiol A Chem 211, 32-41.

13. Ochoa AL, Tempesti TC, Spesia MB, Milanesio ME, Durantini EN (2011) Synthesis and photodynamic properties of adamantylethoxy Zn(II) phthalocyanine derivatives in different media and in human red blood cells. Eur J Org Chem 50, 280-287. 
14. Allémann E, Rousseau J, Brasseur N, Kudrevich SV, Lewis K, van Lier JE (1996) Photodynamic therapy of tumours with hexadecafluoro zinc phthalocyanine formulated in PEGcoated poly(lactic acid) nanoparticles. Int $J$ Cancer 66, 821-824.

15. Chen J, Chen H, Li Y, Wang J, Chen N (2008) Synthesis and photodynamic activity of a new type of pentalysine 2-carbonylphthalocyanine zinc. Chem Res Chin Univ 29, 2131-2137.

16. Chen, Z, Zhou SY, Chen JC, Deng YC, Luo ZP (2010) Pentalysine beta carbonylphthalocyanine zinc: An effective tumor-targeting photosensitizer for photodynamic therapy. Chem Med Chem 5, 890-898.

17. Wang A, Long L, Zhang C (2011) Synthesis and properties of photo-activable phthalocyanines: a brief overview. J Incl Phenom Macro Chem 71, 1-24.

18. Sekkat N, Bergh H, Nyokong T, Lange N (2011) Like a bolt from the blue: Phthalocyanines in biomedical optics. Molecules, 17, 98-144.

19. Zorlu Y, Ermeydan MA, Dumoulin F, Ahsen V, Savoie H (2009) Glycerol and galactose substituted zinc phthalocyanines: Synthesis and photodynamic activity. Photochem Photobiol Sci 8, 312-319.

20. Iqbal Z, Chen J, Chen Z, Huang M (2015) Phthalocyanine-biomolecule conjugated photosensitizers for targeted photodynamic therapy and imaging. Curr Drug Metab 16, 816-832.

21. Taratula O, Schumann C, Naleway MA, Pang AJ, Chon KJ (2013) A multifunctional theranostic platform based on phthalocyanine-loaded dendrimer for image-guided drug delivery and photodynamic therapy. Mol Pharmacol 10, 3946-3952.

22. Mfouo-Tynga I, Houreld NN, Abrahamse H (2013) Evaluation of cell damage induced by irradiated zincphthalocyanine-gold dendrimeric nanoparticles in a breast cancer cell line. biomed $J$ 41, 254-259.

23. Samaana N, Zhongb Q, Fernandeza J, Chena G, Hussaina AM, Zhengc S, Wangb G , Chena Q-H (2014) Design, synthesis, and evaluation of novel heteroaromatic analogs of curcumin as anti-cancer agents. Eur J Med Chem 75, 123-131.

24. Wang X, Ma D, Olson WC, Heston WD (2011) In vitro and in vivo responses of advanced prostate tumors to PSMA ADC, an auristatin-conjugated antibody to prostate-specific membrane antigen. Mol Cancer Ther, 10, 1728-1739.

25. Kuroda k, Liu H, Kim S, Guo M, Navarro V, Bander NH (2010) Saporin toxin-conjugated monoclonal antibody targeting prostate-specific membrane antigen has potent anticancer activity. Prostate 70, 1286-1292.

26. Liu T, Wu LY, Choi JK, Berkman CE (2010) Effectiveness of oral iron to manage anemia in longterm hemodialysis patients with the use of ultrapure dialysate. Int $J$ Oncol 36, 777-783.

27. Watanabe R, Hanaoka H, Paik CH, Wu AM, Choyke PL, Kobayashi H (2015) Photoimmunotherapy tar- geting prostate-specific membrane antigen: Are antibody fragments as effective as antibodies. $J$ Nucl Med $56,140-147$.

28. Kirk KL (2006) Selective fluorination in drug design and development: an overview of biochemical rationales. Curr Topi Med Chem 6, 1447-1455.

29. Martins P, Jesus j, Santos S, Raposo LR, RomaRodrigues C, Baptista PV, Fernandes AR (2015) Heterocyclic anticancer compounds: Recent advances and the paradigm shift towards the use of nanomedicine's tool box. Molecules 20, 16852-16891.

30. Chen Y, Chatterjee S, Lisok A, Minn I, Pullambhatla M, Wharram B, Wang Y, Jin J, et al (2017) A PSMAtargeted theranostic agent for photodynamic therapy. $J$ Photochem Photobiol B Biol 167, 111-116.

31. Youssef TE, ALhamed YA, AL-Sharani SS, Ali KA (2014) Antitumor activity of tetra-substituted zinc phthalocyanines containing $4(3 \mathrm{H})$-quinazolinone derivatives. Rev Chim (Bucharest) 65, 5-11.

32. Elsharif AM, Youssef TE (2019) Synthesis of an activatable tetra-substituted nickel phthalocyanines$4(3 \mathrm{H})$-quinazolinone conjugate and its antibacterial activity. Adv Pharmacol Pharm Sci 2019, ID 5964687.

33. Fadeel DA, Al-Toukhy GM, Elsharif AM, Al-Jameel SS, Mohamed HH, Youssef TE (2018) Improved photodynamic efficacy of thiophenyl sulfonated zinc phthalocyanine loaded in lipid nano-carriers for hepatocellular carcinoma cancer cells. Photodiagnosis Photodyn Ther 23, 25-31.

34. Al Jameel SS, Youssef TE (2018) Investigations on the antitumor activity of classical trifluorosubstituted zinc phthalocyanines derivatives. World J Microbiol Biotechnol 34, 1-7.

35. Mosmann T (1983) Rapid colorimetric assay for cellular growth and survival: Application to proliferation and cytotoxicity assays. J Immunol Methods 65, 55-62.

36. Barbora M, Svatopluk B, Lukas M, Jana J, Katerina LL, Hana K (2015) Phthalocyanine-mediated Photodynamic Treatment of Tumoural and Non-tumoural cell lines. Anticancer Res 35, 3943-3949.

37. Muehlmann LA, Ma BC, Figueiró Longo JP, de Fátima MM, Santos A, Azevedo R (2014) Aluminumphthalocyanine chloride associated to poly(methyl vinyl ether-co-maleic anhydride) nanoparticles as a new third-generation photosensitizer for anticancer photodynamic therapy. Int J Nanomedicine 9, 1199-1206.

38. Fossati N, Karnes RJ, Colicchia M (2018) Impact of early salvage radiation therapy in patients with persistently elevated or rising prostate-specific antigen after radical prostatectomy. Eur Urol 73, 436-444.

39. Agrawal L, Arceo-Mendoza RM, Barnosky A (2016) Prevalence of hypogonadism in low-risk prostate cancer survivors. Fed Pract 33, 37-43. 